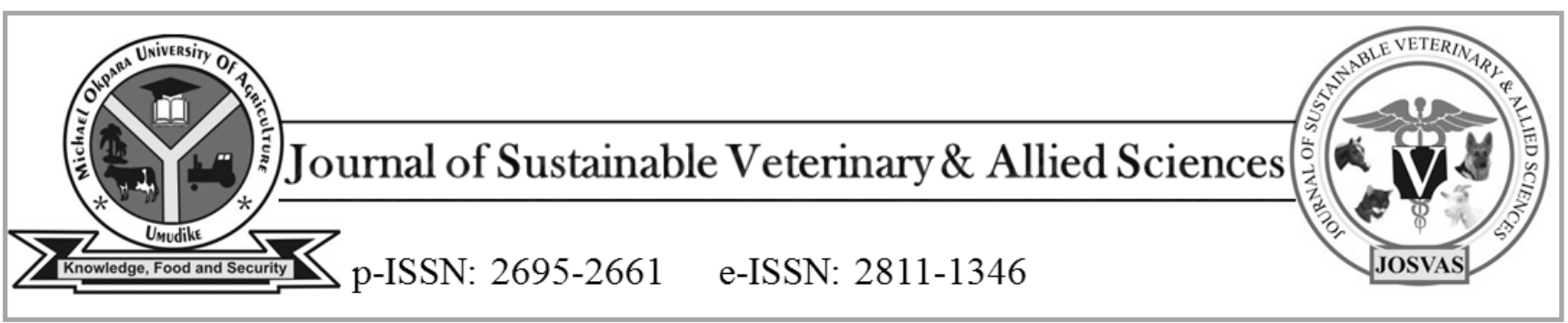

JoSVAS 2021, Vol 1, Issue 1: 52-55

C2021 College of Veterinary Medicine,

Michael Okpara University of Agriculture, Umudike, Nigeria

Original Research Article

\title{
Validation of two human point-of-care glucometers for glucose concentration determination in rats
}

\author{
${ }^{1 *}$ Okorie-Kanu, C.O., ${ }^{2}$ Okorie-Kanu, O.J, ${ }^{1}$ Igbokwe, E.C., ${ }^{1}$ Nwagbara, N.D. \& ${ }^{1}$ Egeonu, M.O \\ ${ }^{l}$ Department of Veterinary Pathology, Michael Okpara University of Agriculture, Umudike, Abia State, ${ }^{2}$ Department of \\ Veterinary Public Health and Preventive Medicine, University of Nigeria, Nsukka, Enugu State, Nigeria.
}

Corresponding author: okorie-kanu.christian@mouau.edu.ng, +2348038993506

\begin{abstract}
Glucose disorders associated with critical illness are common in veterinary medicine and availability of efficient, easy and affordable diagnostic process is vital in combating the menace. Point-of-care glucometers readily come to mind in achieving this goal considering their importance in research and critical case management in veterinary clinics as they are cheap, user friendly, can use small sample quantity and quick generation of results. However, there have been concerns about generation of erroneous results in certain species. This study compared the accuracy and agreement of two point-of-care glucometers for blood glucose determination in rats. Blood samples were obtained from 20 healthy Sprague-Dawley albino rats. Blood ( $2 \mathrm{ml})$ was collected through the retro-bulbar plexus and two glucometers were used to determine the blood glucose concentrations immediately. Thereafter, $1 \mathrm{ml}$ was put into a clean test tube treated with ethylene diamine tetracetic acid and the remaining $1 \mathrm{ml}$ was also put into another test tube without anticoagulant. The samples were processed appropriately to harvest the plasma and serum. Blood glucose test kit was used to measure glucose concentrations in plasma and serum by the glucose oxidase method. Data generated were analysed using one way analysis of variance. Results showed that the mean value generated by one glucometer was relatively comparable with the values generated by the laboratory methods while the other significantly overestimated the glucose concentration. This underscores the importance of validation of glucometers before use in any species as unvalidated glucometers can lead to erroneous research conclusions and clinical decisions with dire consequences
\end{abstract}

Keywords: Accu-chek ${ }^{\circledR}$ Active, glucose determination, point-of-care Glucometer, rats, TysonBio Evolve ${ }^{\circledR}$.

\section{INTRODUCTION}

Diabetes mellitus (DM) is presently one of the most common chronic diseases in the world, affecting about 422 million people worldwide (Marwues et al., 2020), as well as the most common endocrine diseases of dogs, cats and horses. A study of the prevalence of DM in UK cats reported a prevalence of $0.43 \%$ among an insured population of 14,030 cats (McCann et al., 2007) while a range of $0.21 \%$ in Sweden to $1.24 \%$ in the United States have been estimated from university teaching hospitals (Prahl et al., 2007). In Nigeria a prevalence of $0.22 \%$ (Ihedioha \& Enahoro, 2019), may be a far cry of the true prevalence in the country due to paucity of data and attitudinal disinclination of Nigerians to pet and petcare.

In an epidemiological study of diabetes in cats, $48 \%$ of incident cases died or were euthanized during the study period with the highest proportion of these deaths occurring within one year of diagnosis (O'neill et al., 2016).

Clinical management of glucose associated disorders in man and animals is dependent on accurate assessment of blood glucose concentration. (Suvarnavibhaja et al., 2014; Higbie et al., 2015). Adequate blood glucose monitoring requires serial determinations of blood glucose concentrations especially in assessing therapeutic interventions in critical cases and in research settings (Hollis et al., 2008; Mohsenzadeh et al., 2015). Point-of-care glucometers are 
widely used currently in glucose determination because they require little quantity of blood; are cheap, easy to operate and could generate results with the quickest possible time (Lieske et al., 2002). In addition, it has been also found to not only minimize stress in animals but also allow owners to perform serial blood glucose monitoring at home because of the less-invasive nature, thereby reflecting more accurately blood glucose levels. Although these devices have been found useful in some companion animals, there have been concerns about generation of erroneous results in certain species (Cohn et al., 2000; Lieske et al., 2002; Tauk et al., 2015; Okorie-Kanu et al., 2018a; 2018b). As a result of the variation in the values generated by these glucometers, assessment of individual species with individual devices is vital for accuracy and reliability of results (Burdick et al., 2012). Therefore, this study was conducted to compare the values generated by these two devices with the conventional laboratory method for agreement and comparability.

\section{MATERIALS AND METHODS}

Twenty (20) healthy Sprague-Dawley albino rats were used for the study. All protocols in the experiment were approved by College of Veterinary Medicine Research Ethical Committee, Michael Okpara University of Agriculture, Umudike, with clearance number MOUAU/CVM/REC/202117. Random blood samples were collected from ten rats once in a week for two weeks. The rats were individually restrained with minimal stress and 2 $\mathrm{ml}$ of blood was collected from the medial cantus with a capillary tube. Blood glucose levels were determined immediately after blood collection with the two glucometers. The blood sample was divided into two equal parts and 1 part was put into a clean test tube treated with ethylene diamine tetracetic acid (EDTA) while the remaining part was put into another clean test tube without anticoagulant. The samples with anticoagulant were centrifuged immediately while those without anticoagulant were allowed to clot at room temperature for 30 minutes and then centrifuged at $3000 \mathrm{~g}$ and plasma and serum harvested.

\section{POINT-OF-CARE GLUCOMETERS}

Blood glucose was determined using the Accu-chek ${ }^{\circledR}$ active glucometer (Roche Diagnostics GmbH, Nannheim, Germany) based on the glucose dye oxidoreductase mediator reaction while TysonBio Evolve ${ }^{\circledR}$ glucometer (Tyson Bioresearch Inc., Chu Nan, Taiwan) was based on the glucose oxidase method.

\section{PROCEDURE}

The two devices were used to determine glucose concentration according to instructions provided by the manufacturers. Briefly, a test strip was inserted with the orange pad facing up into the glucometer opening for test strip and observed until a flashing blood image appeared on the glucometer screen. A drop of blood was put on the pad of the test strip using a capillary tube for Accu-chek ${ }^{\circledR}$ active while for TysonBio Evolve ${ }^{\circledR}$, the test strip was placed to a drop of blood and the strip pad was filled by capillary action. The blood glucose concentration in $\mathrm{mg} / \mathrm{dl}$ was displayed on the screen after 5 seconds in both methods.

\section{HOW THE TESTS WORK}

In Accu-chek ${ }^{\circledR}$ active, there is a test pad on each test strip containing sensitive chemicals which mix with blood and leads to a chemical reaction, glucose dye oxidoreductase mediator reaction, that causes change in colour of the test area. The meter then converts the colour change to blood glucose concentration. For TysonBio Evolve ${ }^{\circledR}$, a chemical reaction takes place on the test area of the test strip producing a transient electrical current which is converted to blood glucose concentration. The results of both meters are equivalent to plasma glucose values (D'orazio et al., 2005; Steffes \& Sacks, 2005). The ranges of glucose concentration detectable are $10-600 \mathrm{mg} / \mathrm{dl}$ and $20-600 \mathrm{mg} / \mathrm{dl}$ for Accuchek $^{\circledR}$ active and TysonBio Evolve ${ }^{\circledR}$ respectively.

\section{SERUM AND PLASMA}

Blood glucose level was determined using glucose test kit (Quimica Clinica Aplicada, Spain) based on GOD POD method (glucose oxidase method) according to Trinder (1969) for in-vitro determination of blood glucose in serum or plasma.

The working reagent $(1 \mathrm{ml})$ was put into clean and labelled test tubes and $0.01 \mathrm{ml}$ of serum or plasma sample was added to each tube and mixed very well. The mixture was allowed to stand for 10 minutes at room temperature. A standard was prepared as described above. The absorbance of both the samples and standard were read against the contents of the blank at $505 \mathrm{~nm}$ using a Cole Parmer 1200 spectrophotometer (Cole-Parmer Instrument Co., USA).

The glucose concentration was obtained with the formula below:

$\underline{\text { Absorbance of sample }} \times \underline{100}=$ Glucose $(\mathrm{mg} / \mathrm{dl})$

Absorbance of standard 1

The contents of the working reagent include Phosphate buffer (pH 6.8), p-Hydroxybenzoic acid, 4-aminoantipyrine, phenol, glucose oxidase, peroxidase, preservatives and stabilizers. The standard contains $100 \mathrm{mg} / \mathrm{dl}$ equivalent of glucose.

Data generated were analyzed using one One-way Analysis of variance (ANOVA) using Statistical Package for Social Sciences (SPSS) version 16.0 for Windows (SPSS Inc., Chicago, IL). Variant means were separated using the Least Significant Difference (LSD) Method and significance was accepted at $5 \%$ probability level. 


\section{RESULTS}

Results are presented as mean \pm standard error. Although the values generated by the methods varied significantly, the value obtained by one glucometer $(75.05 \pm 3.38 \mathrm{mg} / \mathrm{dl})$ was relatively comparable with the values generated by the laboratory methods $(82.32 \pm 1.77 \& 89.05 \pm 1.47)$ while the other significantly overestimated the glucose concentration $(111.60 \pm 2.86)$. Values obtained from the serum was significantly lower $(p<0.05)$ when compared with the other methods but that of TysonBio Evolve ${ }^{\circledR}$ was far higher than others (Table 1).

glucometer overestimated the glucose concentration in the present study. Similar overestimation of over 50 percent of the normal value was also reported in layer chickens and fish (Okorie-Kanu et al., 2018a; 2018b). Therefore, TysonBio Evolve $^{\circledR}$ may not be a good glucometer for glucose monitoring in rats as this could give erroneous hyperglycemia in normoglycemic rats resulting in erroneous conclusions in research findings. The overestimation in layer chickens and fish was thought to be due to the presence of nuclei in avian and fish red blood cells. The present work has shown that the over estimation in these animals is not attributable to red blood cell nucleation. Therefore further works on this theme are suggested to identify the real cause of the over estimation in some animals.

The clinical implication of glucose

Table I Blood glucose concentration of 20 rats determined with different methods

\begin{tabular}{lllll}
\hline Methods & $\begin{array}{l}\text { Mean } \pm \\
\text { standard error }\end{array}$ & $\begin{array}{l}\text { Standard } \\
\text { deviation }\end{array}$ & $\begin{array}{l}\text { Minimum } \\
\text { Values }\end{array}$ & $\begin{array}{l}\text { Maximum } \\
\text { Values }\end{array}$ \\
\hline Accu-chek ${ }^{\circledR}$ Active & $75.05 \pm 3.38^{\mathrm{a}}$ & 15.13 & 56.00 & 113.00 \\
TysonBioEvolve ${ }^{\circledR}$ & $111.60 \pm 2.86^{\mathrm{b}}$ & 12.80 & 80.00 & 136.00 \\
Serum & $82.32 \pm 1.77^{\mathrm{c}}$ & 7.92 & 71.43 & 100.00 \\
& & & & \\
Plasma & $89.05 \pm 1.47^{\mathrm{d}}$ & 6.57 & 76.19 & 100.00 \\
\hline
\end{tabular}

*Different superscripts in a column indicate significant difference between the mean values $(\mathrm{p}<0.05)$.

\section{DISCUSSION}

The values obtained in the four methods varied significantly from one another but that of the TysonBio Evolve ${ }^{\circledR}$ glucometer was over 40 percent higher than that of Accuchek ${ }^{\circledR}$ Active glucometer and over $20 \%$ higher than values obtained for serum and plasma. While the mean value generated in the plasma was mildly higher than the serum, it still falls under the $15 \%$ range recommended by the American Diabetes Association (Cohn et al., 2000). The higher value obtained in plasma compared to that of serum is due to the immediate separation of the cells from the plasma as red blood cells have been known to consume approximately $10 \%$ of glucose within an hour if not separated. Accu-chek ${ }^{\circledR}$ Active glucometer has been validated for use in humans and many animal species (Johnson et al., 2009; Highie et al., 2015; Okorie-Kanu et al., 2018a, 2018b). This explains why it is slightly higher when compared with the value got in serum. Therefore, Accu-chek ${ }^{\circledR}$ Active glucometer may be used in rats for screening or for research purposes with reasonable accuracy. TysonBio Evolve ${ }^{\circledR}$ and serum $(89.05 \pm 1.47)$.

overestimation or underestimation is wrong diagnosis and subsequently inappropriate treatment. Perhaps, there is no perfect device or protocol in most clinical diagnosis. Certainly, two similar devices or protocols will not produce exactly the same result on a tested sample. A range of value is always allowed for errors. Such a range should not be wide enough to push a normal patient with normoglycaemia to hyperglycemia or hypoglycaemia (ADA, 1995, Cohn et al., 2000). However, the margin of variation in the present study is too wide especially for TysonBio Evolve $^{\circledR}(111.60 \pm 2.86)$

This underscores the immense benefits of validation of glucometers before use in any species. Also, the common test kits utilized in various labs may be underreporting glucose concentrations in both humans and animals due to improper handling of samples. However, since the overestimation of glucose concentration by TysonBio Evolve $^{\circledR}$ is consistent and proportionate in certain species including layer chickens and fish, this research becomes important due to the fact that numerous medical supplies including some glucometer test strips were virtually scarce or nowhere to be found during the lockdown following the Covid 19 pandemic. The knowledge of the proportionate increase will help in correcting for the overestimation especially when it is the only test strip available. Also, for reliable glucose results in researches, plasma should be used instead of serum because of the effects of red blood cells.

Conclusion: Accu-chek ${ }^{\circledR}$ Active glucometer may be used in rats for screening or for research purposes with reasonable accuracy. 


\section{REFERENCES}

American Diabetes Association (ADA) (1995). Selfmonitoring of blood glucose. Diabetes Care, 18, 47 -52 .

Burdick, S., Mitchell M.A., Neil, J., Heggem, B., Whittington, J. \& Aciemo, M.J. (2012). Evaluation of two pointof-care meters and a portable chemistry analyzer for measurement of blood glucose concentrations in juvenile white tailed deer (Odocoileus virginianus). Journal of American Veterinary Medical Association, 240, 596 - 599.

Cohn, L.A., McCaw, D.L., Tate, D.J. \& Johnson, J.C. (2000). Assessment of five portable blood glucose meters, a point-of-care analyzer, and colour test strips for measuring blood glucose concentrations in dogs. Journal of American Veterinary Medical Association, 216, 198 - 202.

D’orazio, P., Burnett, R.W., Fogh-Andersen, N., Jacobs, E., Kuwa, K., Kulpmann, W.R., Larsson, L., Lewenstam, A., Maas, A.H.J., Mager, G., Naskalski, J.W. \& Okorodudu, A.O. (2005). Approved International Federation of Clinical Chemistry (IFCC) recommendation on reporting results for blood glucose (Abbreviated). Clinical Chemistry, 51, 1573 - 1576.

Higbie, C.T., Esher, D. \& Bello, N.M. (2015). Evaluation of three point-of-care meters and a portable veterinary chemistry analyzer for measurement of blood glucose concentrations in black-tailed prairie dogs (Cynomys ludovicianus). American Journal of Veterinary Research, 76,532 - 539.

Hollis, A.R., Furr M.O., Magdesian KG, Axon, J.E., Ludlow, V. \& Corley, K.T.T. (2008). Blood glucose concentrations in critically ill neonatal foals. Journal Veterinary Internal Medicine. 22, 1223 1227.

Ihedioha, J.I. \& Enahoro, G. (2019). Prevalence of diabetes mellitus and reference values for the fasting blood glucose levels of locally available breeds of dogs in Warri, Nigeria. Comparative Clinical Pathology, 28, 1107 - 1112 .

Johnson, B.M., Fry, M.M., Flatlant, B. \& Kirk, C.A. (2009). Comparison of a human portable blood glucose meter and automated chemistry analyser for measurement of blood glucose concentration in dogs. Journal of American Veterinary Medical Association, 235, 1309 - 1313.

Lieske, C.L., Ziccardi, M.H., Mazet, J.A.K., Newman, S.H. \& Gardner, I.A (2002). Evaluation of 4 handheld blood glucose monitors for use in seabirds rehabilitation. Journal of Avian Medicine and Surgery, 16, 277 - 285.

Marques, A.M., Linhares, B.S, Novaes, R.D., Freitas, M.B.,I,Sarandy, M.M. \& Goncalves, R.V. (2020). Effects of the amount and type of carbohydrates used in type 2 diabetes diets in animal models: a systematic review. PLoS ONE 15(6), e0233364.

McCann, T.M., Simpson, K.E., Shaw, D.J., Butt, J.A., GunnMoore, D.A. (2007). Feline diabetes mellitus in the UK: the prevalence within an insured cat population and a questionnaire-based putative risk factor analysis. Journal of Feline Medicine \& Surgery, 9, $289-299$.

Mohsenzadeh, M.S., Zaeemi, M., Razmyar, J \& Azizzadeh, M. (2015). Comparism of a point-of-care glucometer and a laboratory autoanalyser for measurement of blood glucose concentrations in domestic pigeons (Columba livia domestica). Journal of Avian Medicine and Surgery, 29,181186.

O’Neill, D.G. Gostelow, R., Orme, C., Church., D.B., Niessen, S.J.M., Verheyen, K. \& Brodbelt, D.C. (2016). Epidemiology of Diabetes Mellitus among 193,435 Cats Attending Primary-Care Veterinary Practices in England. Journal of Veterinary Internal Medicine, 30, $964-972$.

Okorie-Kanu, C.O., Igbokwe, C.E., Nwagbara, N.D. \& Egeonu, M.O. (2018a). Evaluation of point of-care glucometers for blood glucose determination in layer chickens. Journal of Science and Sustainable Technology, 1(2), 245 - 250.

Okorie-Kanu, C.O., Igbokwe, C.E., Okorie-Kanu, O.J., Aba, P.E. \& Nwagbara, N.D. (2018b). Comparison of Point-of-Care Glucometers for Blood Glucose Determination in Cows, Goats and Fish. Proceedings of the 43rd Annual Conference of the Nigerian Society for Animal Production, 43, 957 959.

Prahl, A., Guptill, L., Glickman, N.W., Tetrick, M. \& Glickman, L.T. (2007). Time trends and risk factors for diabetes mellitus in cats presented to veterinary teaching hospitals. Journal of Feline Medicine \& Surgery, 9, 351-358.

Steffes, M. W. \& Sacks, D. B. (2005). Measurement of circulating glucose concentrations: The time is now for consistency among methods and types of samples. Clinical Chemistry, 51, 1569 - 1570.

Suvarnavibhaja, S., Yuennan, P., Tangwangwiwat, R., Kuaha, A. \& Yibchokeana, S. (2014). Reliability of portable blood glucose meters for use in small animal hospital. Thailand Journal of Veterinary Medicine, 44, 195 - 200.

Tauk, B.S., Drobatz, K.J., Wallace, K.A. \& Hess, R.S. (2015). Correlation between glucose concentrations in serum, plasma, and whole blood measured by point-of-care glucometer and serum glucose concentration measured by an automated biochemical analyzer for canine and feline blood samples. Journal of American Veterinary Medical Association, 246, 1327-1333.

Trinder, P. (1969). Determination of glucose using glucose oxidase with an alternative oxygen acceptor. Annals of Clinical Biochemistry, 6: 24 - 27.

Article history: Received: July 27, 2021,

Revised: August 12, 2021

Accepted: August 13, 2021 